\title{
Regional anesthesia catheter tunnelling: a simpler approach
}

\author{
Duncan Maguire, MD • Mullein Thorleifson, MD, FRCPC
}

Received: 14 November 2019/Revised: 19 November 2019/Accepted: 21 November 2019/Published online: 17 December 2019

(C) Canadian Anesthesiologists' Society 2019

\section{To the Editor,}

The recent letter by Lin et al. highlighted the benefits of tunnelling regional anesthesia catheters and outlined a novel technique. ${ }^{1}$ As the authors indicate, tunnelling the catheter is an underutilized method to minimize the risks of catheter dislodgement and infection. They described a retrograde technique using a Tuohy needle and flexible tip wire that avoids formation of a "skin bridge".

While their system clearly works, its requirement for retrograde wiring arguably makes it somewhat complex. We offer a simpler method using readily available supplies that both eliminates the skin bridge and mitigates the potential risk of wire kinking and catheter shearing. Our technique utilizes a standard regional catheter insertion kit (17G Tuohy needle), a scalpel, and a 16G 83-mm Angiocath $^{\mathrm{TM}}$ (Becton Dickinson Infusion Therapy Systems Inc.; Sandy, UT, USA). With this method, the Tuohy needle is inserted and the regional block (or epidural) catheter is threaded (as per standard regional technique) after which the Tuohy needle remains in place.

This letter is accompanied by a reply. Please see Can J Anesth 2020; 67: this issue.

Electronic supplementary material The online version of this article (https://doi.org/10.1007/s12630-019-01554-x) contains supplementary material, which is available to authorized users.

D. Maguire, MD $(\bowtie) \cdot$ M. Thorleifson, MD, FRCPC

Department of Anesthesiology, Perioperative and Pain Medicine, University of Manitoba, L2035 - 409 Tache Avenue, Winnipeg, MB, Canada

e-mail: ummaguid@myumanitoba.ca
A scalpel is then used to make a small skin incision (2-3 $\mathrm{mm}$ ) beneath the Tuohy needle, which serves as the starting point for a subcutaneous tunnel. The skin where the tunnel will be created is then infiltrated with local anesthetic and the Angiocath is inserted into the incision and through the subcutaneous tissue to exit the skin at the desired location. During this process, the regional catheter remains protected by the covering Tuohy needle. The Angiocath is then slid off its needle and its Luer-lock end is cut off with sterile scissors. The Tuohy needle can then be removed, and the regional catheter is threaded through the in situ Angiocath without risk of shearing or damage by the needle bevel (as acknowledged by Lin et al.). ${ }^{1}$ Once the regional catheter emerges through the distal tunnel puncture site, the Angiocath can be removed. The principal advantages of this technique are that it only requires a single needle pass through the subcutaneous tissue and avoids retrograde catheter threading through the Tuohy needle, across the bevel. It also uses equipment that is readily available, avoids formation of the skin bridge, and minimizes the potential for catheter damage. 

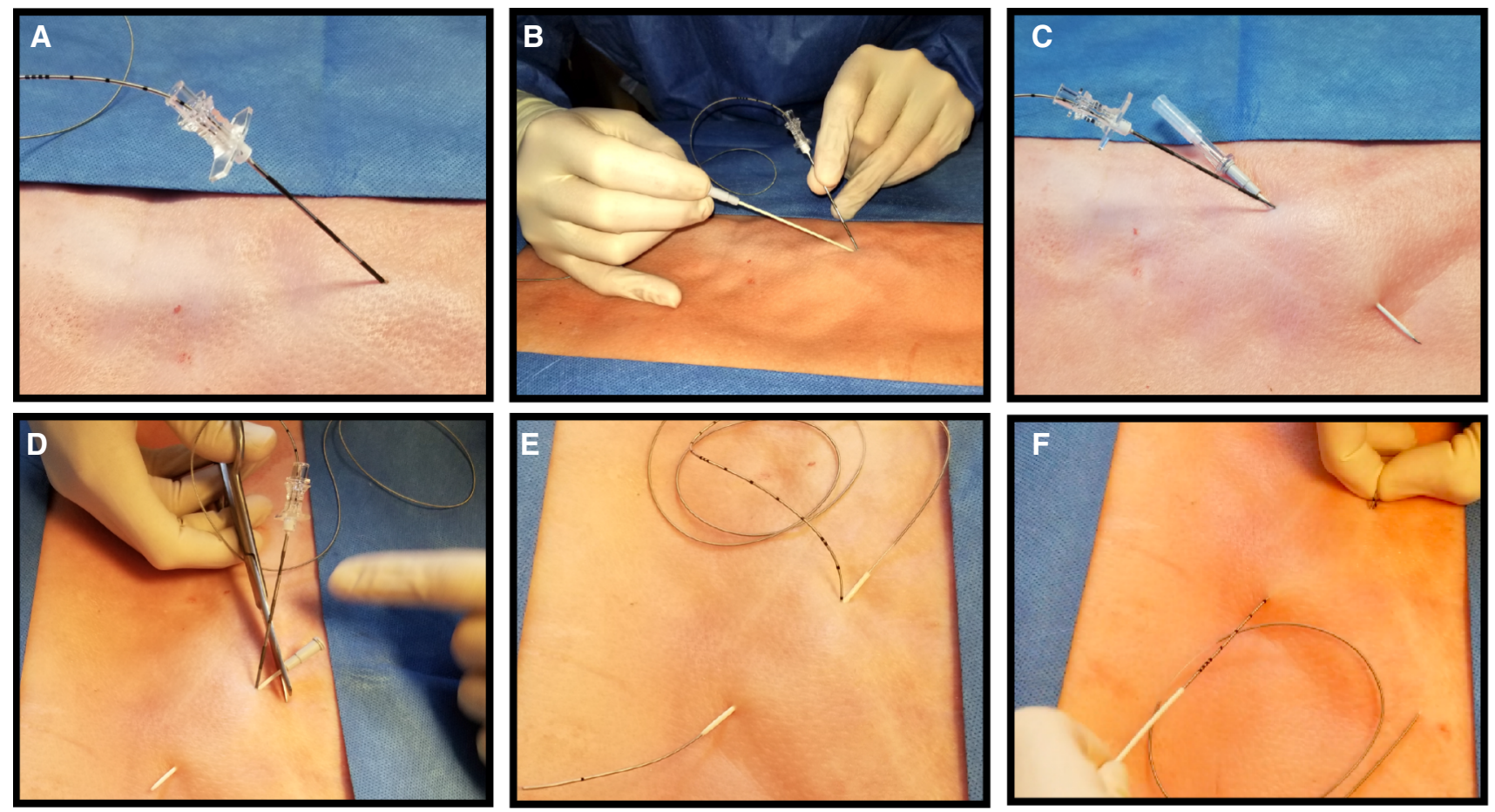

Figure Technique to tunnel a regional anesthesia or epidural catheter. A) Tuohy needle and catheter are sited in standard fashion. B) A skin incision is made and the $16 \mathrm{G}$ Angiocath is inserted alongside the Tuohy needle, which protects the catheter. C) The Angiocath exits the subcutaneous tissue. D) The needle has been removed from the Angiocath and the Luer lock is cut off with sterile

Author contributions D. Maguire and M. Thorleifson contributed to the writing of this letter.

\section{Conflicts of interest None.}

Financial statement None.

Editorial responsibility This submission was handled by Dr. Steven Backman, Associate Editor, Canadian Journal of Anesthesia. scissors. E) The Tuohy needle has been removed and the catheter is threaded through the Angiocath. F) The Angiocath is removed while holding the catheter loop with counter traction; note is made of the catheter depth from original insertion site (see eVideo in the Electronic Supplementary Material).

\section{Reference}

1. Lin C, Reece-Nguyen T, Tsui BC. A retrograde tunnelling technique for regional anesthesia catheters: how to avoid the skin bridge. Can J Anesth 2019; DOI: https://doi.org/10.1007/ s12630-019-01505-6.

Publisher's Note Springer Nature remains neutral with regard to jurisdictional claims in published maps and institutional affiliations. 